\title{
A Case Study of the Application of a Modified Method to Measure Global Solar Irradiance
}

Technical Report NREL/TP-560-37184

February 2006

F.P. Rael

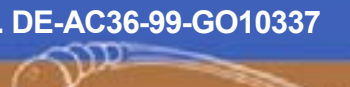




\section{A Case Study of the Application of a Modified Method to Measure Global Solar Irradiance}

Technical Report NREL/TP-560-37184

February 2006

\section{F.P. Rael}

Prepared under Task No. WUID.5600 and Inter-Agency Work Order No. 353926 


\section{NOTICE}

This report was prepared as an account of work sponsored by an agency of the United States government. Neither the United States government nor any agency thereof, nor any of their employees, makes any warranty, express or implied, or assumes any legal liability or responsibility for the accuracy, completeness, or usefulness of any information, apparatus, product, or process disclosed, or represents that its use would not infringe privately owned rights. Reference herein to any specific commercial product, process, or service by trade name, trademark, manufacturer, or otherwise does not necessarily constitute or imply its endorsement, recommendation, or favoring by the United States government or any agency thereof. The views and opinions of authors expressed herein do not necessarily state or reflect those of the United States government or any agency thereof.

Available electronically at http://www.osti.gov/bridge

Available for a processing fee to U.S. Department of Energy and its contractors, in paper, from:

U.S. Department of Energy

Office of Scientific and Technical Information

P.O. Box 62

Oak Ridge, TN 37831-0062

phone: 865.576 .8401

fax: 865.576 .5728

email: mailto:reports@adonis.osti.gov

Available for sale to the public, in paper, from:

U.S. Department of Commerce

National Technical Information Service

5285 Port Royal Road

Springfield, VA 22161

phone: 800.553 .6847

fax: 703.605.6900

email: orders@ntis.fedworld.gov

online ordering: http://www.ntis.gov/ordering.htm 


\section{Acknowledgments}

This research was supported by the Office of Biological and Environmental Research of the U.S. Department of Energy as part of the Atmospheric Radiation Measurement (ARM) Program. Solar radiation measurements from the ARM Climate Research Facility were essential to accomplishing this research. I would like to thank Afshin Andreas. The software he wrote was critical to this work. Mary Anderberg and Pete Gotseff made this work smoother by generously providing me with technical assistance and logistical support. Steve Wilcox, Daryl Myers, and Ibrahim Reda also were helpful advisors and great sources of information. Tom Stoffel oversaw and guided me through the entire endeavor. 


\section{Executive Summary}

Climate change research requires accurate measurements of downwelling, total hemispheric (global) solar irradiance. Until the performance of commercially available pyranometers can be improved, a better understanding of the radiometer response characteristics is needed to reduce the current measurement uncertainty levels of 5\%-10\%. The abilities of a pyranometer to respond equally to radiance from any part of the sky dome and to maintain thermal equilibrium under changing atmospheric conditions are important pyranometer design considerations. The resulting angular and zero-offset responses are currently the largest contributors to thermopile-based pyranometer measurement uncertainty.

Fortunately, the calibration of pyranometers by the component summation method provides insight to the instrument-specific response characteristics that are important for reducing measurement uncertainties. Outdoor pyranometer calibration results show the variations of responsivity $\left(\mu \mathrm{V} / \mathrm{Wm}^{-2}\right)$ related to the solar zenith angle $(Z)$ and the effective sky temperature. In this paper, we will describe the benefits of applying pyranometer responsivity (Rs) that varies as a function of solar zenith angle $[\operatorname{Rs}(Z)]$ compared with the traditional single-value pyranometer responsivity at $45^{\circ}$ solar zenith angle $[\operatorname{Rs}(45)]$.

Using data from 23 measurement stations in the Southern Great Plains (developed for the Atmospheric Radiation Measurement [ARM] Program), we quantified the effects of applying a pyranometer responsivity function $[\operatorname{Rs}(Z)]$ to measurements taken between June 2003 and May 2004. We considered the effects of this technique on the corrected irradiance measurements (e.g., Wm ${ }^{-2}$ ) and on the changes to the automatic data quality assessments required for the ARM data.

The improvements are greater for clear sky conditions when the direct beam solar irradiance dominates the pyranometer response. Our results suggest Rs(45) is adequate for cloudy sky conditions. The degree of data quality improvements varies with measurement station and the associated pyranometer in use at the time. 


\section{Table of Contents}

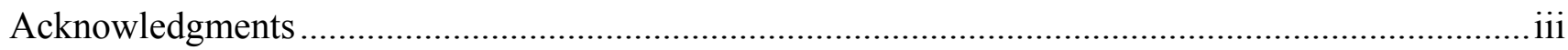

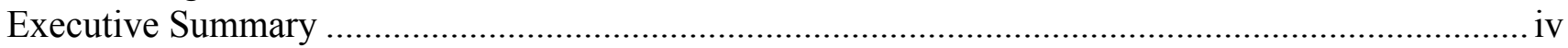

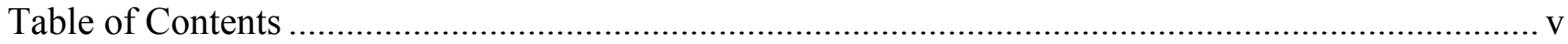

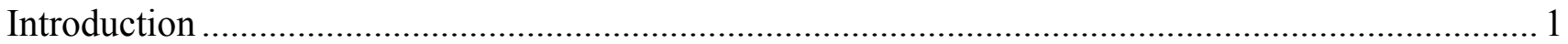

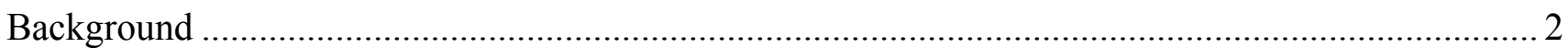

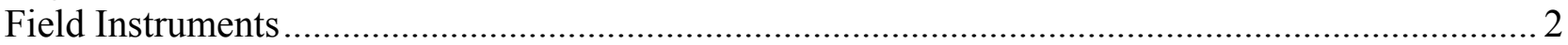

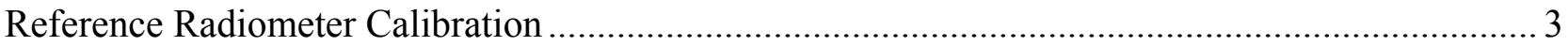

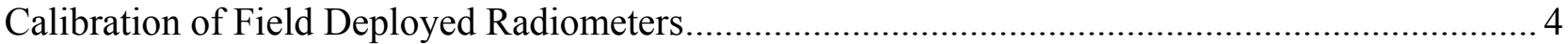

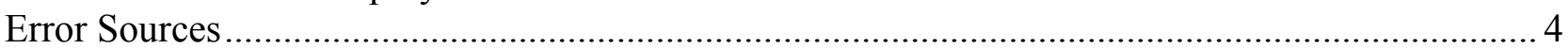

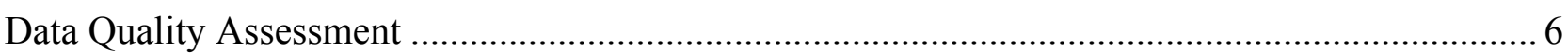

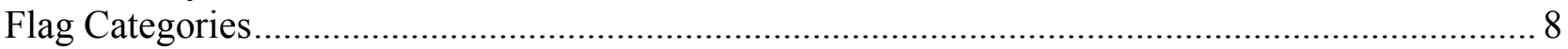

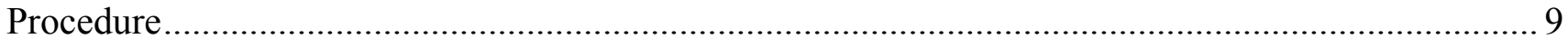

Extra Steps for Data that Use Rs as a Function of Zenith Angle ................................................ 11

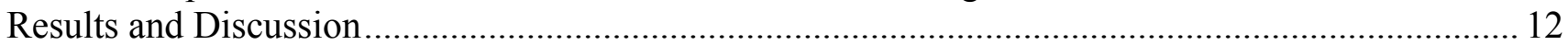

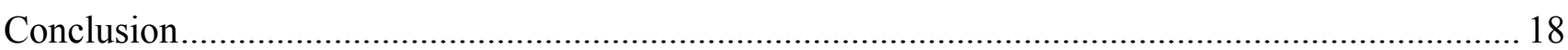

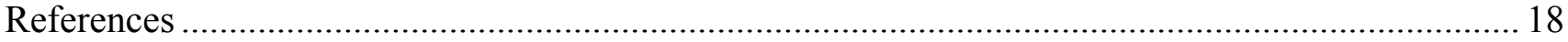




\section{Introduction}

The Atmospheric Radiation Measurement Program (ARM) deploys about 100 pyranometers as part of a 23-station network in the Southern Great Plains (SGP) to study climate change. The study of climate change requires radiation measurements with an uncertainty below $2 \%$. Thus, there has been a sustained effort to reduce this uncertainty.

The outputs of unshaded global pyranometers depend on the incident angle of the direct beam component of the radiation being measured. Figure 1 shows a typical scatter plot for the calibration of The Eppley Laboratory, Inc. model Precision Spectral Pyranometers (PSPs) with Rs as a function of solar zenith angle.

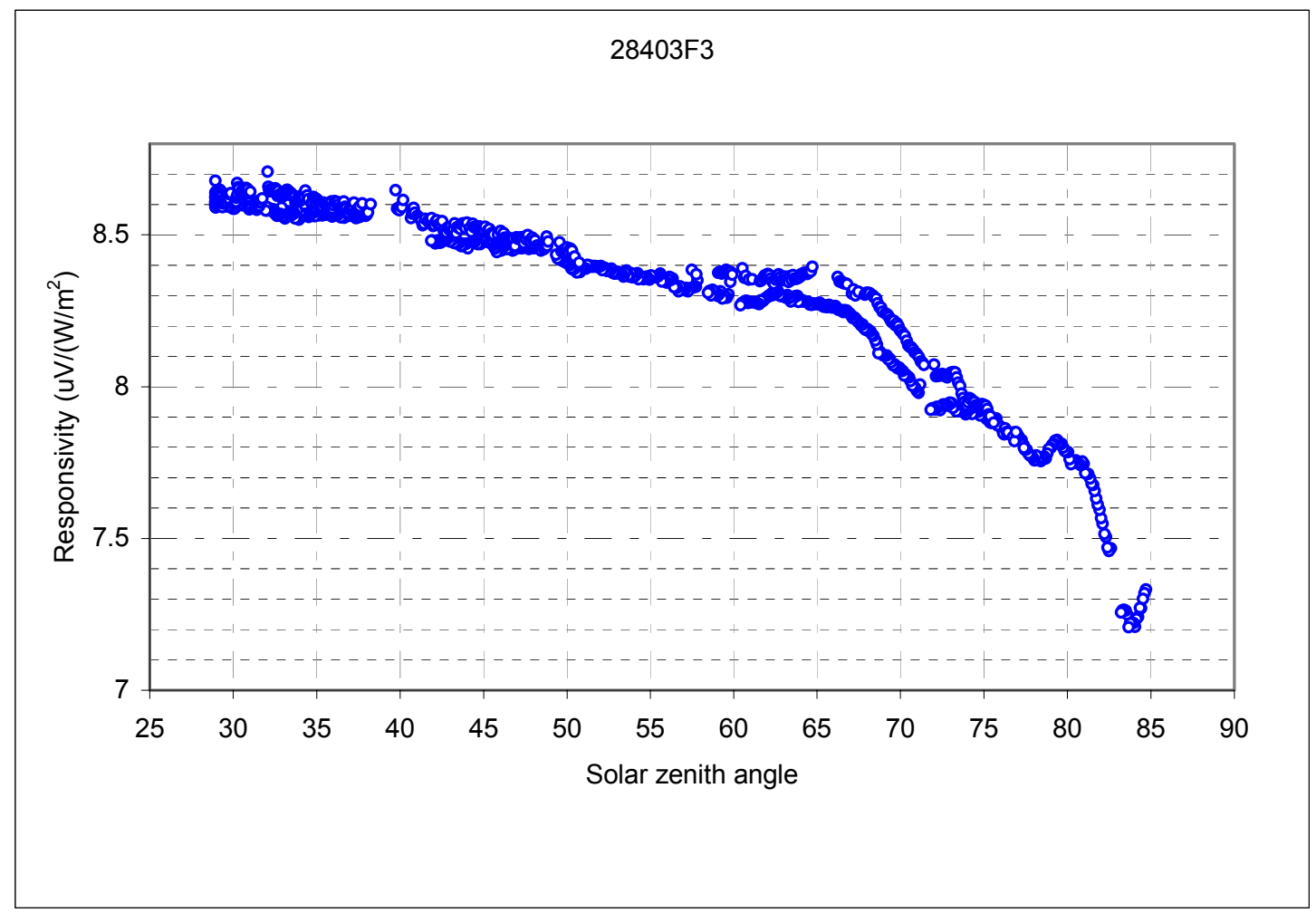

Figure 1. Component summation calibration data for PSP serial number 28403F3.

The most widespread method of making global solar radiation measurements is to use a pyranometer deployed with a constant Rs, namely Rs(45). Depending on the individual instrument, season, and time of day, errors introduced by using this single Rs method can be $5 \%-10 \%$.

A new method addresses the error from the use of Rs(45) by using a 49-order polynomial fit to the calibration Rs curve as a function of zenith angle for global pyranometers [1]. Two separate functions are associated with each pyranometer, one for the morning and one for the afternoon. This method is applied only to the readings of the global pyranometer. The functions are of the form: 


$$
R s(Z)=\sum_{i=0}^{n} a_{i} \cos ^{i} Z_{i}
$$

Where

$$
\begin{array}{lll}
R s(\mathrm{Z})= & \text { Rs function of a pyranometer } \\
\mathrm{N} & = & \text { number of data points used to solve the }(\mathrm{n}+1)^{\text {th }} \text { order equation } \\
a_{i} & = & \text { the } i^{\text {th }} \text { coefficient } \\
\mathrm{Z}_{i} & = & \text { the } i^{t h} \text { solar zenith angle }
\end{array}
$$

Broadband Outdoor Radiometer Calibration (BORCAL) is the process used by ARM for calibration of the pyranometers it uses in the field. The BORCAL calibration report includes the Rs at each $2^{\circ}$ solar zenith angle (i.e. at $\left.\mathrm{Z}=0^{\circ}, 2^{\circ}, 4^{\circ}, \ldots, 90^{\circ}\right)$. The $(\mathrm{n}+1)$ zenith angles and their corresponding Rs's are substituted in Equation 2:
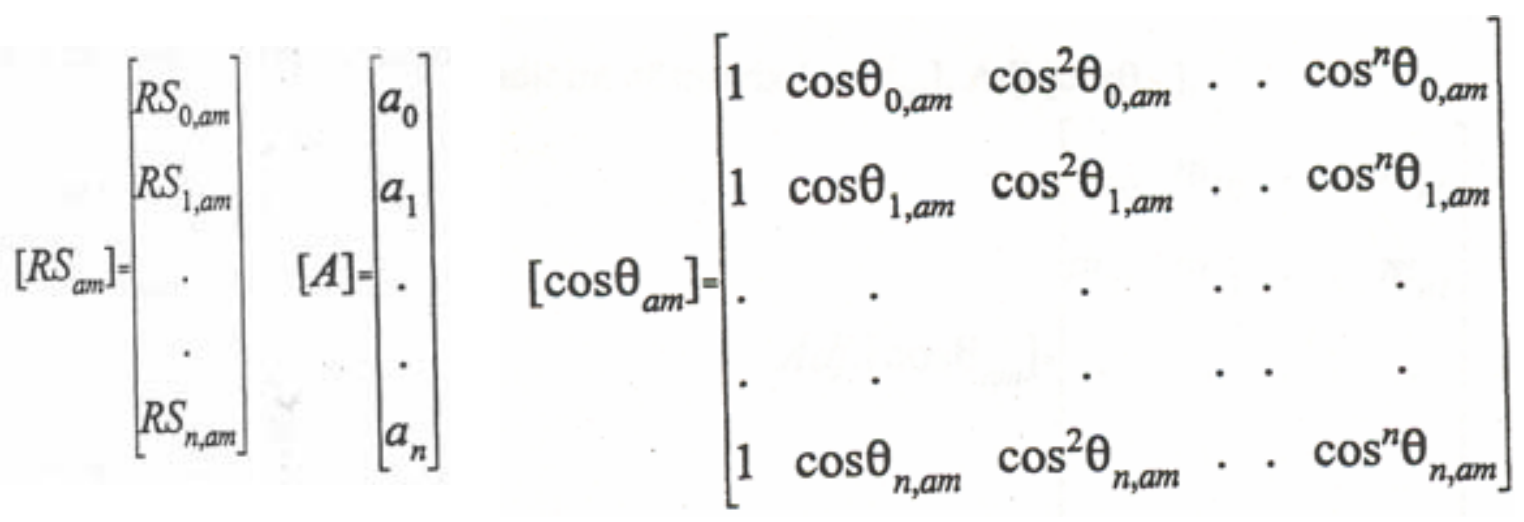

(2)

The coefficients are then calculated with a series of matrix operations and manipulations as described in [1].

This new method is a major improvement over the Rs(45) approach for measuring clear sky data. Field conditions, however, are substantially different from the selected clear-sky controlled calibration conditions.

The purpose of this report is to quantify the effectiveness of this method under field conditions. For this case study, data collected for all sky and ambient conditions for the entire Southern Great Plains (SGP) network from June 2003 to May 2004 were analyzed. An emphasis was placed on the three stations at the Central Facility and daytime data in which the solar zenith angle was less than $80^{\circ}$.

\section{Background}

\section{Field Instruments}

The short wave radiometers deployed at SGP as part of the Solar and Infrared Radiation Station (SIRS) instrumentation are: 
- Eppley model Normal Incidence Pyrheliometers (NIPs), which measure direct normal solar irradiance. Direct radiation is defined as the radiation of the solar beam only as measured by a surface normal to the solar beam.

- Eppley model 8-48 pyranometers, which measure diffuse horizontal solar irradiance. Diffuse radiation is defined as the sky-only radiation on a surface parallel to the horizon.

- Eppley model Precision Spectral Pyranometers (PSPs), which measure global parameters. Global radiation is defined as the sky only plus the solar disk radiation on a surface parallel to the horizon.

All three instruments use a thermopile detector. A more thorough description of how the instruments work is available on the ARM Web site at www.arm.gov/instruments.

\section{Reference Radiometer Calibration}

Pyrheliometers: Electrically self-calibrating Absolute Cavity Radiometers (ACRs) are used to calibrate the field NIPs are traceable to the World Radiometric Reference (WRR) developed and maintained by the World Radiation Center in Davos, Switzerland. The WRR is the only internationally recognized measurement reference for solar irradiance (Fröhlich, 1977; Fröhlich, 1991, and Fröhlich et al., 1995).

Pyranometers: There is no world standard for calibrating reference pyranometers. In the absence of a reference pyranometer, NREL uses commercial pyranometers with minimal zero offset characteristics to calibrate reference diffuse pyranometers. The reference pyranometer for measuring diffuse radiation is calibrated with a modified ASTM shade/unshade method (ASTM E913) developed at NREL (Reda et al. 2003). The shade/unshade method - modified or otherwiseoperates on the basis of the following equation:

$$
\mathrm{Rs}=(\mathrm{U}-\mathrm{S}) / \mathrm{B} \cos \mathrm{Z}
$$

Where

$$
\begin{array}{lll}
\mathrm{Rs} & = & \text { responsivity }\left[\mu \mathrm{V} /\left(\mathrm{W} / \mathrm{m}^{\wedge} 2\right)\right] \\
\mathrm{U} & = & \text { output voltage of unshaded pyranometer }[\mu \mathrm{V}] \\
\mathrm{S} & = & \text { output voltage of shaded pyranometer }[\mu \mathrm{V}] \\
\mathrm{B} & = & \text { direct beam radiation }\left[\mathrm{W} / \mathrm{m}^{\wedge} 2\right] \\
\mathrm{Z} & = & \text { solar zenith angle }
\end{array}
$$

$\mathrm{U}$ and $\mathrm{S}$ are measured simultaneously with this method, which, of course, is impossible. NREL's method, however, corrects for this necessary evil by using a continuously shaded control instrument to reference to the test instrument. This modification allows the engineer to calculate what the test instrument's shade value would have been even as the unshaded irradiance is measured. The shaded measurement is achieved by using a simple ratio between the output voltages of the test and control instruments:

$$
\mathrm{R}=\mathrm{S}_{\text {test }} / \mathrm{S}_{\text {control }}
$$

Where

$$
\begin{array}{ll}
\mathrm{S}_{\text {test }}= & \text { output voltage of shaded test instrument } \\
\mathrm{S}_{\text {control }}= & \text { output voltage of shaded control instrument }
\end{array}
$$


The responsivity of reference diffuse pyranometers is determined from the shade calibration data taken at a $45^{\circ}$ solar zenith angle. To account for responsivity variations caused by the relative solar azimuth angle, the calibration is performed at six pyranometer angles with respect to the sun: $0^{\circ}, 60^{\circ}$, $120^{\circ}, 180^{\circ}, 240^{\circ}$, and $300^{\circ}$ azimuth angles. The resulting averaged responsivity at the $45^{\circ}$ solar zenith is a good approximation for the average radiance of a diffuse pyranometer. That is, the pyranometer will respond in balance to the local horizon brightening caused by multiple scattering effects and circumsolar brightening near the solar disk due to forward scattering by the atmosphere. The $45^{\circ}$ responsivity also accounts for the annual time-weighted average of solar zenith angles for mid-latitude measurement stations.

\section{Calibration of Field Deployed Radiometers}

The pyranometers deployed at SGP were calibrated with the ASTM standard G167 summation calibration method. Both the PSP and 8-48 model pyranometer were unshaded during calibration and compared to reference direct and diffuse radiation measurements. The global, direct, and diffuse radiation can be referenced to each other by using this equation:

$$
\text { Global }=\text { Diffuse }+ \text { Direct }[\cos Z]
$$

Where

$$
\mathrm{Z}=\text { solar zenith angle }
$$

This equation is at the core of calibration and data quality control for downwelling shortwave radiometer. The deployed pyranometers were calibrated under clear sky conditions during the summer when the minimum solar zenith angle is less than $45^{\circ}$.

As mentioned earlier, the field-deployed NIPs are calibrated by comparing them directly to a WRRtraceable ACR.

\section{Error Sources}

Besides the cosine error response for a pyranometer, a multitude of areas throughout the data collection process introduce uncertainty. Reference 2 explains and quantifies the cumulative uncertainty in calibration of field-deployed pyranometers. It was determined that there is a $1.84 \%$ uncertainty in the calibration of pyranometers and a $1.59 \%$ uncertainty in the calibration of the pyrheliometer. The uncertainty results are duplicated in Table 1 for pyranometers and Table 2 for pyrheliometers. 
Table 1. Uncertainties in Individual Rs for PSP Summation Calibration.

\begin{tabular}{|c|c|c|}
\hline TYPE A & Statistical UNC (\%) & STD UNC (\%) \\
\hline WRR Transfer & 0.200 & 0.200 \\
\hline $\operatorname{Cos}(z)\left(2^{\circ} Z\right.$ bin $)$ & 0.010 & 0.005 \\
\hline $\operatorname{Dif}(2.5 \% \mathrm{D}=>0.25 \%$ Ref.) & 0.125 & 0.063 \\
\hline Temperature $\left(2^{\circ} \mathrm{Z}\right.$ bin $)$ & 0.100 & 0.050 \\
\hline Data Logger Precision & 0.005 & 0.0025 \\
\hline ACR (wind, T) & 0.025 & 0.013 \\
\hline Temp Chg $\left(10^{\circ} \mathrm{C}\right)$ & 0.250 & 0.125 \\
\hline Diff Offset B\&W & 0.125 & 0.063 \\
\hline UUT IR OFFSET & 0.250 & 0.125 \\
\hline EMI/Thermal EMF & 0.010 & 0.005 \\
\hline Subtotal & 0.455 & 0.286 \\
\hline \multicolumn{3}{|l|}{ TYPE B } \\
\hline Logger Bias (9 uV/10 mv) & 0.090 & 0.090 \\
\hline WRR Std U95 & 0.300 & 0.300 \\
\hline $\operatorname{Cos}(z) ; Z<89^{\circ} ; 2^{\circ}$ bin & 0.010 & 0.005 \\
\hline Temperature $\left(2^{\circ} \mathrm{Z}\right.$ bin $)$ & 0.100 & 0.050 \\
\hline ACR Bias (M, wind, $T)$ & 0.025 & 0.013 \\
\hline Temp B (event to event) $10^{\circ} \mathrm{C}$ & 0.250 & 0.125 \\
\hline Diff Offset B\&W & 0.125 & 0.063 \\
\hline UUT IR OFFSET & 0.625 & 0.625 \\
\hline Spectral Error & 0.500 & 0.250 \\
\hline EMI/Thermal EMF & 0.010 & 0.005 \\
\hline Subtotal & 0.910 & 0.872 \\
\hline TOTAL & 1.017 & 0.918 \\
\hline \multicolumn{3}{|l|}{ Effective Degree of Freedom $>100$} \\
\hline Coverage Factor $(\mathrm{k}) \quad 2$ & & \\
\hline Expanded Uncertainty $1.84 \%$ & & \\
\hline
\end{tabular}


Table 2. Uncertainties for $95 \%$ Confidence Interval for Individual Rs for Pyrhleiometer Calibration.

\begin{tabular}{|l|c|c|}
\hline & Statistical UNC (\%) & STD UNC (\%) \\
\hline TYPE A & & 0.200 \\
\hline WRR Transfer & 0.500 & 0.050 \\
\hline Temp Response UUT & 0.005 & 0.0025 \\
\hline Data Logger Precision & 0.200 & 0.100 \\
\hline Linearity (empirical) & 0.025 & 0.013 \\
\hline ACR (wind, T) & 0.250 & 0.125 \\
\hline Tracking Variations & 0.500 & 0.500 \\
\hline Spectral (window) & 0.010 & 0.005 \\
\hline EMI/Thermal EMF & 0.802 & 0.615 \\
\hline Subtotal & & \\
\hline & & 0.090 \\
\hline TYPE B & 0.090 & 0.300 \\
\hline Logger Bias (9 uV/10 mv) & 0.300 & 0.250 \\
\hline WRR Std U95 & 0.500 & 0.013 \\
\hline Temp Response UUT & 0.025 & 0.125 \\
\hline ACR Bias (M, wind, T) & 0.250 & 0.500 \\
\hline Temp B (event to event) 10 & 0.500 & 0.0125 \\
\hline Spectral Error & 0.250 & 0.005 \\
\hline Tracking Bias & 0.010 & 0.504 \\
\hline EMI/Thermal EMF & 0.851 & \\
\hline Subtotal & & $\mathbf{0 . 9 1 8}$ \\
\hline & $\mathbf{1 . 1 6 9}$ & \\
\hline TOTAL & & \\
\hline Effective Degree of Freedom >100 & & \\
\hline Coverage Factor (k) 2 & & \\
\hline Confidence Interval 95\% & & \\
\hline Expanded Uncertainty 1.59\% & & \\
\hline
\end{tabular}

In addition to uncertainty error introduced in the calibration, field conditions such as aging of the instrument, site maintenance issues, and variable ambient conditions introduce further uncertainty.

\section{Data Quality Assessment}

SERI QC is used to assess the quality of the solar ARM data (NREL, 1993). Most SERI QC test failures in the SGP SIRS data are three-component failures. The three-component test is essentially a normalized form of Equation 5:

$$
\mathrm{Kn}=\mathrm{Kt}+\mathrm{Kd}
$$

Where

\begin{tabular}{|c|c|c|c|}
\hline $\mathrm{Kn}$ & $=$ & In / Io & direct beam transmittance \\
\hline Kt & $=$ & It / (Io $\cos Z)$ & effective global horizontal transmittance \\
\hline $\mathrm{Kd}$ & $=$ & Id / (Io $\cos Z)$ & effective diffuse horizontal transmittance \\
\hline Io & $=$ & \multicolumn{2}{|c|}{ extraterrestrial direct normal radiation } \\
\hline In & $=$ & \multicolumn{2}{|c|}{ direct normal radiation at the Earth's surface } \\
\hline It & $=$ & \multicolumn{2}{|c|}{ total global horizontal radiation at the Earth's surface } \\
\hline Id & $=$ & \multicolumn{2}{|c|}{ diffuse horizontal radiation at the Earth's surface } \\
\hline $\mathrm{Z}$ & $=$ & \multicolumn{2}{|c|}{ solar zenith angle } \\
\hline
\end{tabular}


Operating in k-space is advantageous because it allows the engineer to see irradiance values as a percentage of maximum possible. Each global k-space value is compared with the summed direct and diffuse k-space values. Any discrepancies to Equation 6 are quantified and, based on the magnitude of the inequality, flags are assigned to each parameter. Table 3 presents the complete table for the SERI QC flagging system. The SERI QC suite includes one- and two-component tests in addition to the three-component test. However, "Because three-component tests are more reliable, threecomponent flags are retained regardless of previous one- or two-component results" (SERI QC Manual). A graphical description of the one- and two-component tests is provided in Figure 2. The criteria for both tests are set empirically. $\mathrm{Kn}, \mathrm{Kt}$, and $\mathrm{Kd}$ are merely normalized values of diffuse, global, and direct radiation measurements normalized to the concurrent extraterrestrial solar irradiance.

Table 3. Flagging Convention for SERI QC.

\begin{tabular}{|c|c|}
\hline Flag & Description \\
\hline 00 & Untested (raw data) \\
\hline 01 & Passed one-component test; data fall within min-max limits of $\mathrm{K}_{\mathrm{t}}, \mathrm{K}_{\mathrm{n}}$, or $\mathrm{K}_{\mathrm{d}}$ \\
\hline 02 & Passed two-component test; data fall within 0.03 of the Gompertz boundaries \\
\hline 03 & $\begin{array}{l}\text { Passed three-component test; data come within } \pm 0.03 \text { of satisfying } \\
\mathrm{K}_{\mathrm{t}}=\mathrm{K}_{\mathrm{n}}+\mathrm{K}_{\mathrm{d}}\end{array}$ \\
\hline 04 & Passed visual inspection; not used by SERI_QC \\
\hline 05 & Failed visual inspection; not used by SERI_QC \\
\hline 06 & Value estimated; passes all pertinent SERI_QC test \\
\hline 07 & Failed one-component test; lower than allowed minimum \\
\hline 08 & Failed one-component test; higher than allowed maximum \\
\hline 09 & Passed three-component test but failed two-component test by $>0.05$ \\
\hline $10-93$ & $\begin{array}{l}\text { - Failed two- or three-component tests in one of four ways. } \\
\text { - To determine the test failed and the manner of failure (high or low), } \\
\text { examine the remainder of the calculation (flag }+2) / 4 \text {. } \\
\text { REM Failure } \\
\text { O Parameter too low by three-component test }\left(\mathrm{K}_{\mathrm{t}}=\mathrm{K}_{\mathrm{n}}+\mathrm{K}_{\mathrm{d}}\right) \\
1 \text { Parameter too high by three-component test }\left(\mathrm{K}_{\mathrm{t}}=\mathrm{K}_{\mathrm{n}}+\mathrm{K}_{\mathrm{d}}\right) \\
2 \text { Parameter too low by two-component test }(\mathrm{Gompertz} \text { boundaries) } \\
3 \text { Parameter too high by two-component test (Gompertz boundaries) } \\
\text { The magnitude of the test failure (distance in K-units) is determined from: } \\
\mathrm{d}=\text { (INT (flag }+2) / 4) / 100 \text {. }\end{array}$ \\
\hline $94-97$ & $\begin{array}{l}\text { Data fall into a physically impossible region where } K_{n}>K_{t} \text { by } K \text {-space distances of } \\
0.05 \text { to } 0.10 \text { (94), } 0.10 \text { to } 0.15(95), 0.15 \text { to } 0.20(96) \text { amd } \pm 0.20(97) \text {. }\end{array}$ \\
\hline 98 & Not used \\
\hline 99 & Missing data \\
\hline
\end{tabular}

Upon completion of automatic flagging, manual analysis begins. 


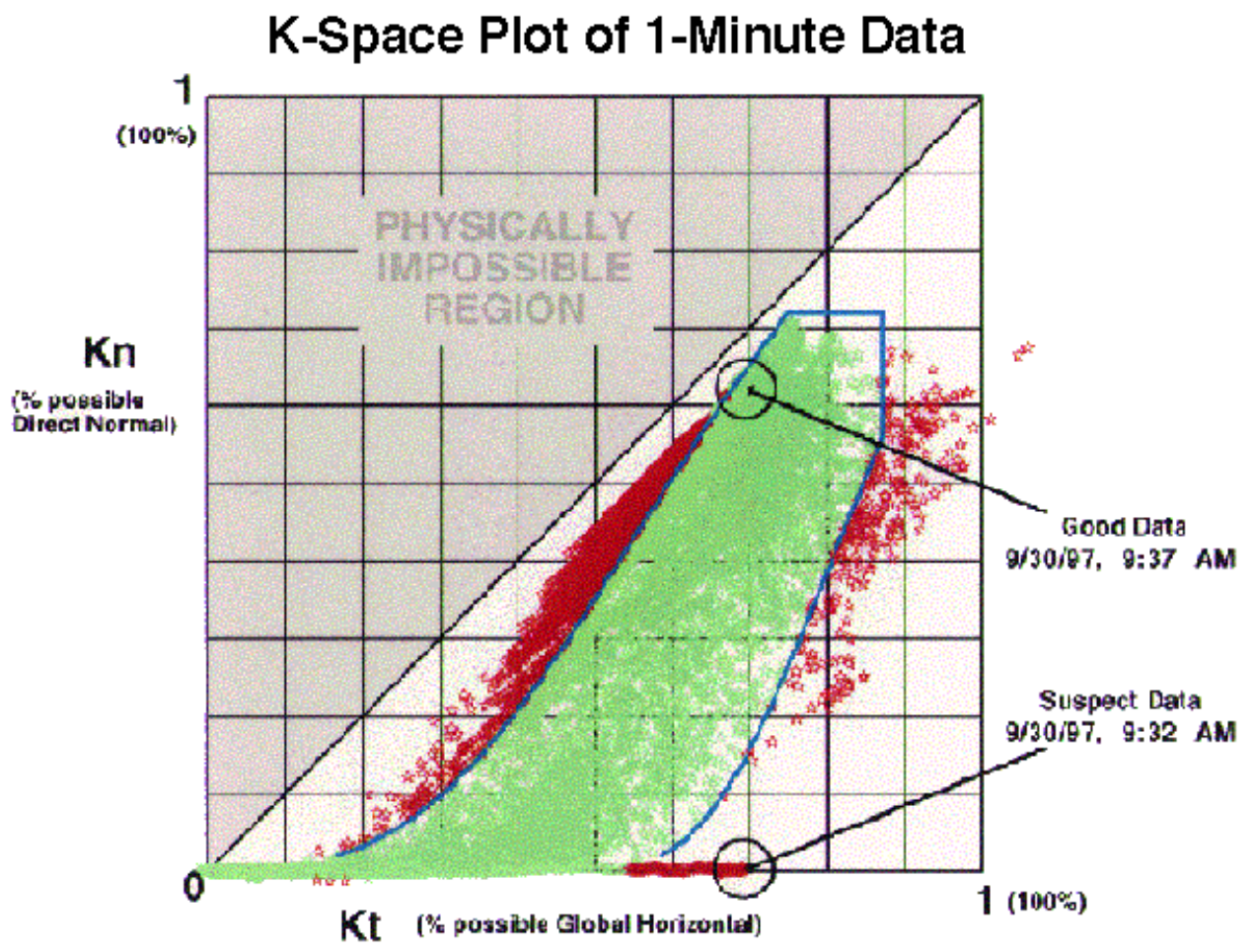

Figure 2. SERI QC data boundaries for two-element quality assessment.

The horizontal and vertical blue lines in Figure 2 represent the limits for the one component test. Any data exceeding the maximum set value of either $\mathrm{Kt}$ or $\mathrm{Kn}$ will be flagged as unacceptable. The onecomponent test is the only test conducted at solar zenith angles of greater than $80^{\circ}$. Note that the red, blue, and green color scheme in Figure 2 has no relation to the ARM assigned colors for good, suspect, and unacceptable data.

The polynomial curves are called Gompertz boundaries and further restrict the acceptable values for the global and direct components. All data must fall between the two curves to be acceptable. This is the 2-component test.

It is important to remember that the three-component test is preponderant among the three tests. It is tighter than, and supersedes the one- and two-component tests.

\section{Flag Categories}

For the purposes of ARM data quality assessment, the SERI QC flags are divided into four different categories, as shown in Table 4.

Table 4. Table of SERI QC Flags Categorized by ARM Color.

\begin{tabular}{|c|c|c|}
\hline Color & SERI QC Flags & Description of Data \\
\hline & & \\
\hline Green & $1-6,10-20$ & Good \\
\hline Yellow & $21-41$ & Suspect \\
\hline Red & $7,8,42-98$ & Unacceptable \\
\hline Black & 99 & Missing \\
\hline
\end{tabular}




\section{Procedure}

The ARM SGP SIRS data are reformatted, stored, and transferred many times between acquisition at the instrument to quality assessment at NREL. Figure 3 presents the flow of SGP SIRS data from collection to quality assessment.

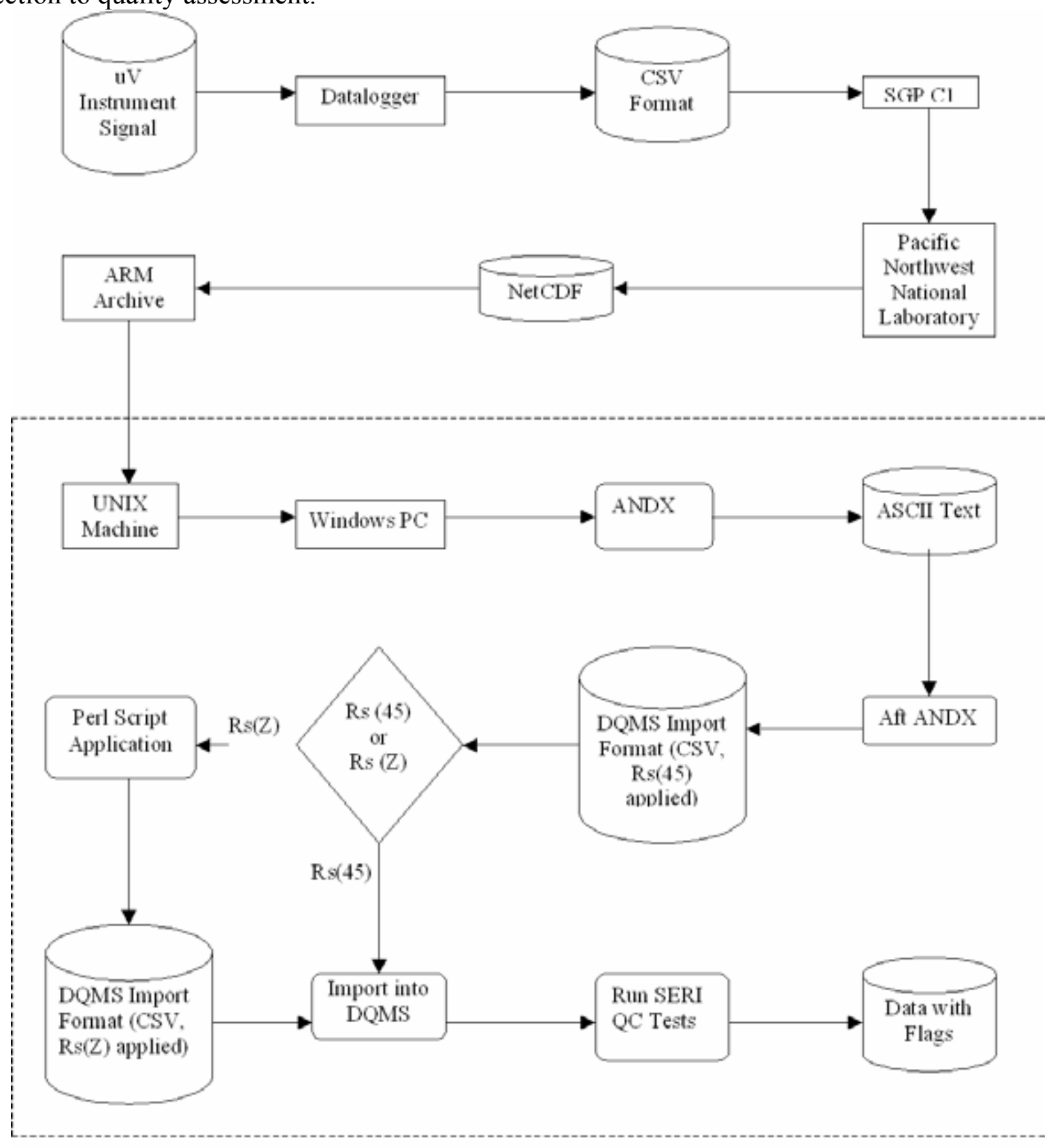

NREL Boundary

Figure 3. Electronic flow of SGP data. 
The output of the radiometers, referred to as raw data, is a milliVolt $(\mathrm{mV})$ thermopile signal. This voltage is the input into the data logger where the constant calibration factor $(\mathrm{Cf}=1 / \mathrm{Rs})$ at $45^{\circ}$ is applied to the output of the global pyranomter. The data are now in engineering units $\left(\mathrm{W} / \mathrm{m}^{\wedge} 2\right)$. SGP's central facility downloads these data hourly from the data loggers at all the extended facilities. Pacific Northwest National Laboratory then ingests these data, flags them with SERI QC, converts them to NetCDF (Network Common Data Form), and stores them at the ARM archive. Because the ARM program collects and stores a huge amount of data, the NetCDF format was developed to give ARM a self-documenting and space-effective mode of storage. The ARM archive is the public access server for all ARM data. NREL has standing orders with the ARM archive for weekly delivery of the most recent available SGP/SIRS data. The weekly transfer of NetCDF data from a designated archive delivery area to a UNIX computer at NREL has been preprogrammed and is accomplished automatically.

After an arbitrary time interval, the data - still in NetCDF - are manually sent via file transfer protocol (ftp) from the UNIX computer to a Windows PC at NREL for further processing.

Once the data are on the PC, they are reformatted from NetCDF to ASCII by using an application, ARM NetCDF Data Extract (ANDX), developed specifically for ARM. ANDX converts the NetCDF file to an ASCII text file. ANDX also gives the user the ability to accept or reject any parameter he or she chooses from the data file being processed.

The ARM archive offers various levels of processed data files. For example, one could order raw data files or highly processed data that are referred to as value added products (VAPs). NREL accesses the "b1" level NetCDF files stored at the ARM archive: the b1 indicates that the parameters are in engineering units and the data have been quality checked. They are one-minute data streams and are not VAPs. NREL ignores the flags and uses ANDX to extract only the six radiometer measurements from the NetCDF file, for which ANDX provides the capability.

"In- house" software, called AftANDX, is then used after ANDX to reformat the date-time stamp into the Data Quality Management System (DQMS) compatible import format, comma separated variable (CSV) format, and to insert the individual site ID's into the files. DQMS is software developed specifically for managing solar energy data. The data, now in comma separated variable (CSV) format with the appropriate site and date-time stamp are ready to be imported into DQMS.

At this point two separate data sets are created for this study. The first data set will have global irradiance determined from the Rs(45). This is the data set that has been traditionally stored, quality assessed, and disseminated. The second data set will account for the global pyranomer's Rs change with respect to the solar zenith angle $(\operatorname{Rs}(Z))$. The description of the extra steps needed for applying the variable Rs to the global pyranometer readings follow. 


\section{Extra Steps for Data that Use Rs as a Function of Zenith Angle}

Before these data are ready for import into DQMS, the raw data readings in millivolts must first be "backed out" with the Rs(45) calibration factor. The Rs(Z) function can then be applied to the data. All of this is accomplished with the Perl calculator, a Perl script program that can convert large amounts of data at a time by systematically backing out the constant Rs readings and applying the Rs function to the raw data. The inputs are the initial data file, the serial number of the global pyranometer being converted, the $45^{\circ} \mathrm{Rs}$ that applied to the input file, and the 49 coefficients for the Rs function. The output is a data file converted from the use of the constant Rs $45^{\circ}$ to a file that applies the Rs function. The site ID is then changed to differentiate this dataset with that of the constant Rs. This is necessary to allow both datasets in DQMS simultaneously.

Now both datasets can be imported into DQMS, which merely involves properly configuring the DQMS import drivers. The record definitions must also be modified in accordance with the proper ID stamps to accommodate the multiple datasets for each measurement site.

Once the import is completed, automated testing by DQMS per the SERI QC test criteria is performed. This operation is also a trivial matter of configuration of test definitions and test drivers. According to Table 3, three flags are assigned to each one-minute data record, one for each downwelling shortwave SIRS parameter: direct, diffuse, and global. Figure 4 presents a typical view of a DataView plot, with time-series plots of upwelling longwave, downwelling longwave, and upwelling shortwave included in the image, in addition to the ARM data quality flag colors under the time axis for each of the three downwelling shortwave parameters.

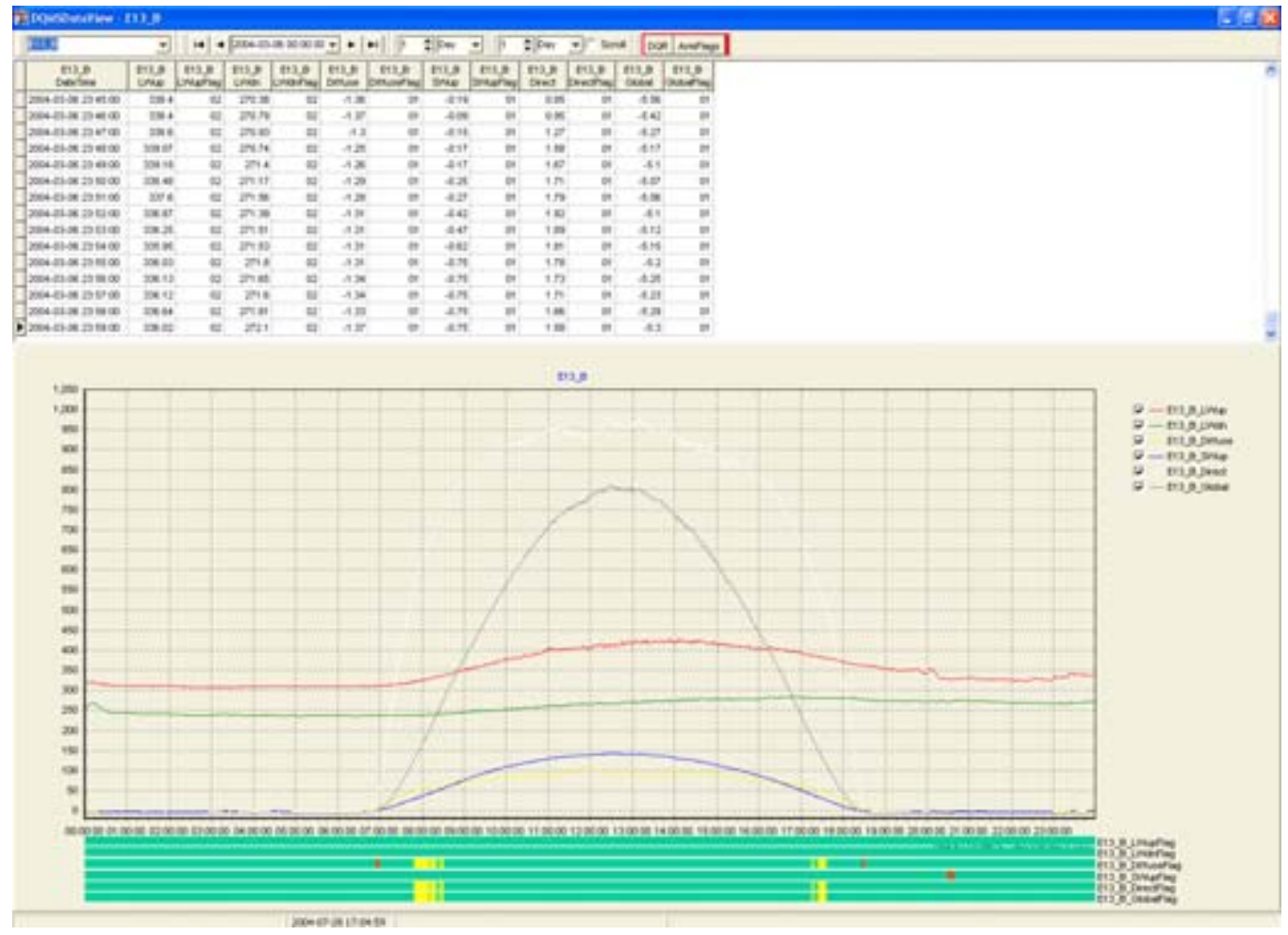

Figure 4. Typical DataView image with corresponding data in tabular form. 


\section{Results and Discussion}

Table 5 lists the performance of the entire SGP network for the time period beginning June 1, 2003 and ending May 31, 2004, including nighttime data and daytime data that were recorded when the solar zenith angle was greater than $80^{\circ}$, where the three-component test is not applied. The first four columns of Table 5 show results of using Rs(45) for the entire test period. The next four columns show results of using $\operatorname{Rs}(Z)$ for the entire test period, and the last four columns show the difference between the two methods.

The most notable change is the major reduction in the amount of the yellow, or questionable data. This is because the vast majority of yellow data are flagged because of three component failures at zenith angles approaching $80^{\circ}$ (e.g., Equation 3 is not satisfied by the independent measurements), which is the area where the Rs function works best.

There is little change in the number of red data, mostly because many nighttime empirical limit failures are caused by the known zero-offset characteristics of the Model PSP. Naturally, the data that are below empirical limits will have exceptionally low values and occur under cloudy sky conditions, where application of the Rs function is insignificant. Most daytime red data are below empirical limits as well. For daytime data to be below empirical limits Equation 8 must be satisfied.

$$
\mathrm{DS}<.05 \operatorname{ETR} \operatorname{Cos}(\mathrm{Z})
$$

Where

$$
\begin{array}{lll}
\mathrm{ETR} & = & \mathrm{I}_{0} * \mathrm{ERV} \\
\mathrm{I}_{0} & = & \text { solar constant }=1367 \mathrm{Wm}^{-2} \\
\mathrm{ERV} & = & \left(\mathrm{r}_{\mathrm{o}} / \mathrm{r}\right)^{2} \\
\mathrm{r}_{\mathrm{o}} & = & \text { mean sun-Earth distance } \\
\mathrm{r} & = & \text { instantaneous sun-Earth distance }
\end{array}
$$

Extraterrestrial radiation (ETR) is the amount of global radiation at the top of the atmosphere.

The insignificance of the Rs function under cloudy skies is illustrated in Table 6. These data were taken from the three stations at the Central Facility: C1, E13, and BRS. The data constitute two consecutive hours from each site for each month during the test period. In other words, there were 72 hours of data in this set before the data below empirical limits were removed. Each of the three sites contributed 24 hours; 2 hours for each month of the test period. Both $\operatorname{Rs}(45)$ and $\operatorname{Rs}(Z)$ data had to be flagged as below empirical limits for that data point to be discarded. All the data in this set were measured at least 2.5 hours after sunrise and 2.5 hours before sunset. Also, the direct measurement had to be less than $50 \mathrm{Wm}^{-2}$ for the data to be considered cloudy and thus eligible for inclusion in this dataset. The first column categorizes all the data according to arbitrarily selected global irradiance values. The minimum and maximum global measurements in the data set were 41 and $487 \mathrm{Wm}^{-2}$ and this is reflected in the first column of Table 6 . The next three columns are averaged values. For example, the $77.1 \mathrm{Wm}^{-2}$ is the average irradiance of the 1069 data points in the $41-100 \mathrm{Wm}^{-2} \mathrm{bin}$. The $0.21 \mathrm{Wm}^{-2}$ is the average change in global irradiance using $\operatorname{Rs}(45)$ instead of $\operatorname{Rs}(\mathrm{Z})$. The -0.019 is the corresponding average change in SERI QC flag value. The averages were computed by averaging both data set together. A negative value in this column represents an improvement because the flag will have been reduced to a lesser magnitude. 
Table 5. Performance of the SGP Network, June 1, 2003 to May 31, 2004.

\begin{tabular}{|c|c|c|c|c|c|c|c|c|c|c|c|c|}
\hline \multirow{3}{*}{ Station } & \\
\hline & \multicolumn{4}{|l|}{$\operatorname{Rs}(45)$} & \multicolumn{4}{|l|}{$\operatorname{Rs}(Z)$} & \multicolumn{4}{|l|}{ Change } \\
\hline & Green & Yellow & Red & Missing & Green & Yellow & Red & Missing & Green & Yellow & Red & Missing \\
\hline BRS & 83.65 & 5.95 & 9.28 & 1.13 & 88.13 & 1.84 & 8.90 & 1.13 & 4.48 & -4.11 & -0.37 & 0.00 \\
\hline C1 & 95.48 & 1.82 & 0.85 & 1.86 & 97.09 & 0.20 & 0.85 & 1.86 & 1.62 & -1.62 & 0.00 & 0.00 \\
\hline E1 & 93.39 & 2.14 & 0.85 & 3.62 & 95.22 & 0.31 & 0.85 & 3.62 & 1.82 & -1.83 & 0.00 & 0.01 \\
\hline E2 & 96.12 & 1.22 & 1.52 & 1.14 & 96.87 & 0.50 & 1.49 & 1.14 & 0.75 & -0.72 & -0.03 & 0.01 \\
\hline E3 & 95.16 & 1.38 & 1.17 & 2.29 & 96.39 & 0.16 & 1.16 & 2.30 & 1.23 & -1.23 & -0.01 & 0.01 \\
\hline E4 & 95.37 & 2.60 & 0.92 & 1.11 & 97.70 & 0.26 & 0.92 & 1.11 & 2.33 & -2.34 & 0.00 & 0.01 \\
\hline E5 & 95.19 & 1.89 & 1.81 & 1.11 & 96.66 & 0.47 & 1.76 & 1.11 & 1.46 & -1.42 & -0.05 & 0.01 \\
\hline E6 & 95.94 & 0.90 & 0.87 & 2.28 & 96.59 & 0.24 & 0.87 & 2.30 & 0.65 & -0.66 & 0.00 & 0.01 \\
\hline E7 & 92.34 & 2.51 & 1.54 & 3.60 & 94.48 & 0.44 & 1.47 & 3.61 & 2.14 & -2.07 & -0.07 & 0.01 \\
\hline E8 & 96.70 & 1.33 & 0.61 & 1.35 & 97.85 & 0.20 & 0.59 & 1.35 & 1.15 & -1.13 & -0.02 & 0.00 \\
\hline E9 & 94.89 & 2.11 & 1.34 & 1.66 & 96.69 & 0.34 & 1.29 & 1.68 & 1.80 & -1.76 & -0.05 & 0.01 \\
\hline E10 & 90.16 & 2.45 & 1.12 & 6.27 & 90.71 & 1.79 & 1.22 & 6.28 & 0.55 & -0.65 & 0.10 & 0.01 \\
\hline E11 & 95.92 & 1.87 & 0.71 & 1.50 & 97.49 & 0.31 & 0.71 & 1.50 & 1.56 & -1.56 & 0.00 & 0.00 \\
\hline E12 & 95.87 & 1.52 & 1.48 & 1.13 & 96.82 & 0.58 & 1.48 & 1.12 & 0.95 & -0.94 & 0.00 & -0.01 \\
\hline E13 & 93.62 & 2.17 & 0.71 & 3.51 & 95.50 & 0.28 & 0.73 & 3.50 & 1.88 & -1.89 & 0.02 & -0.01 \\
\hline E15 & 91.06 & 5.06 & 0.92 & 2.96 & 95.66 & 0.45 & 0.87 & 2.96 & 4.60 & -4.61 & -0.05 & 0.00 \\
\hline E16 & 86.95 & 3.10 & 0.65 & 9.30 & 89.57 & 0.52 & 0.61 & 9.30 & 2.62 & -2.59 & -0.03 & 0.00 \\
\hline E18 & 91.73 & 2.10 & 0.85 & 5.32 & 93.64 & 0.29 & 0.76 & 5.32 & 1.90 & -1.81 & -0.09 & 0.00 \\
\hline E19 & 91.17 & 4.65 & 1.14 & 3.03 & 95.05 & 0.91 & 1.01 & 3.04 & 3.88 & -3.74 & -0.14 & 0.00 \\
\hline E20 & 91.62 & 3.03 & 1.03 & 4.33 & 94.28 & 0.48 & 0.90 & 4.34 & 2.66 & -2.55 & -0.12 & 0.01 \\
\hline E21 & 81.41 & 2.75 & 2.43 & 13.40 & 82.07 & 1.88 & 2.63 & 13.42 & 0.66 & -0.88 & 0.20 & 0.02 \\
\hline E22 & 95.25 & 1.00 & 0.74 & 3.01 & 95.97 & 0.28 & 0.74 & 3.01 & 0.72 & -0.72 & 0.00 & 0.00 \\
\hline E24 & 92.09 & 1.86 & 0.78 & 5.27 & 93.54 & 0.33 & 0.84 & 5.29 & 1.46 & -1.53 & 0.06 & 0.01 \\
\hline E27 & 94.17 & 1.48 & 1.30 & 3.04 & 94.51 & 0.95 & 1.49 & 3.05 & 0.34 & -0.53 & 0.19 & 0.01 \\
\hline
\end{tabular}


Table 6. Cloudy Data from the Central Facility.

\begin{tabular}{|c|c|c|c|c|}
\hline & \multicolumn{3}{|c|}{ Averages } & \\
\hline DS Irradiance $\left(\mathrm{W} / \mathrm{m}^{\wedge} 2\right)$ & Irradiance $\left(\mathrm{W} / \mathrm{m}^{\wedge} 2\right)$ & Change in Irradiance $\left(\mathrm{W} / \mathrm{m}^{\wedge} 2\right)$ & Change in Flag & Data Points in Bin \\
\hline $41-100$ & 77.1 & 0.21 & -0.019 & 1069 \\
\hline $100-200$ & 141.9 & -0.13 & 0.004 & 2049 \\
\hline $200-487$ & 290.0 & 0.15 & 0.015 & 1032 \\
\hline
\end{tabular}

${ }^{*}$ All data that had a flag of 7 were deleted and are not included in this table.

One can also see the inconsequential effect of applying the Rs function under cloudy skies in Figure 5, a DQMS plot for C1 on April 23, 2004. Only the pink Rs(Z) global data are visible because both the Rs(45) global and diffuse are covered by it. At the bottom of the display, the change in flags was virtually nil. E70_E_GlobalFlag represents the flags for the Rs(45) data and E70_D_GlobalFlag represents the $\bar{R} s(Z)$ data.

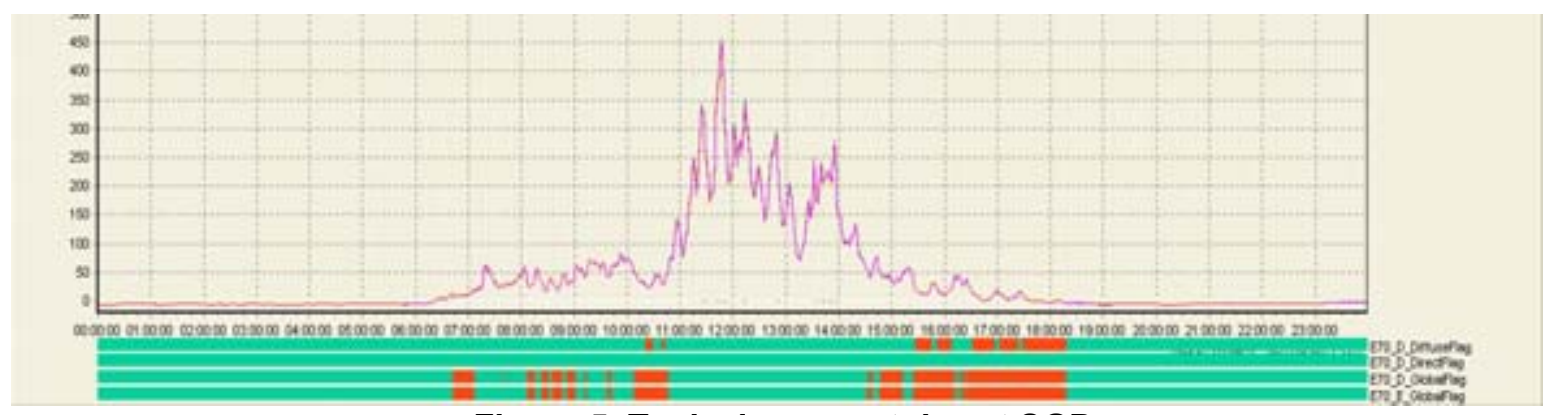

Figure 5. Typical overcast day at SGP .

This usually stands in stark contrast compared to the application of the Rs function on a clear day, such as Figure 6, which is April 27, 2004 at C1, four days after Figure 5. There is a large change in absolute terms in the middle of the day and substantial improvement in flags at high zenith angles in the evening. This is due to the nature of Equation (3), and the fact that flags of 20 or less are still considered green, in accordance with Table 4 . In the particular case of Figure 6 in the middle of the day, while the Rs(45) global data were flagged with SERI QC flags within the magnitude allowed by the ARM Green category, they were nonetheless improved to better SERI QC flags with RS(Z). So the Rs function corrected data that was too high around noon and data that was too low later that same day. This scenario is the most common concerning clear-sky daytime data. 


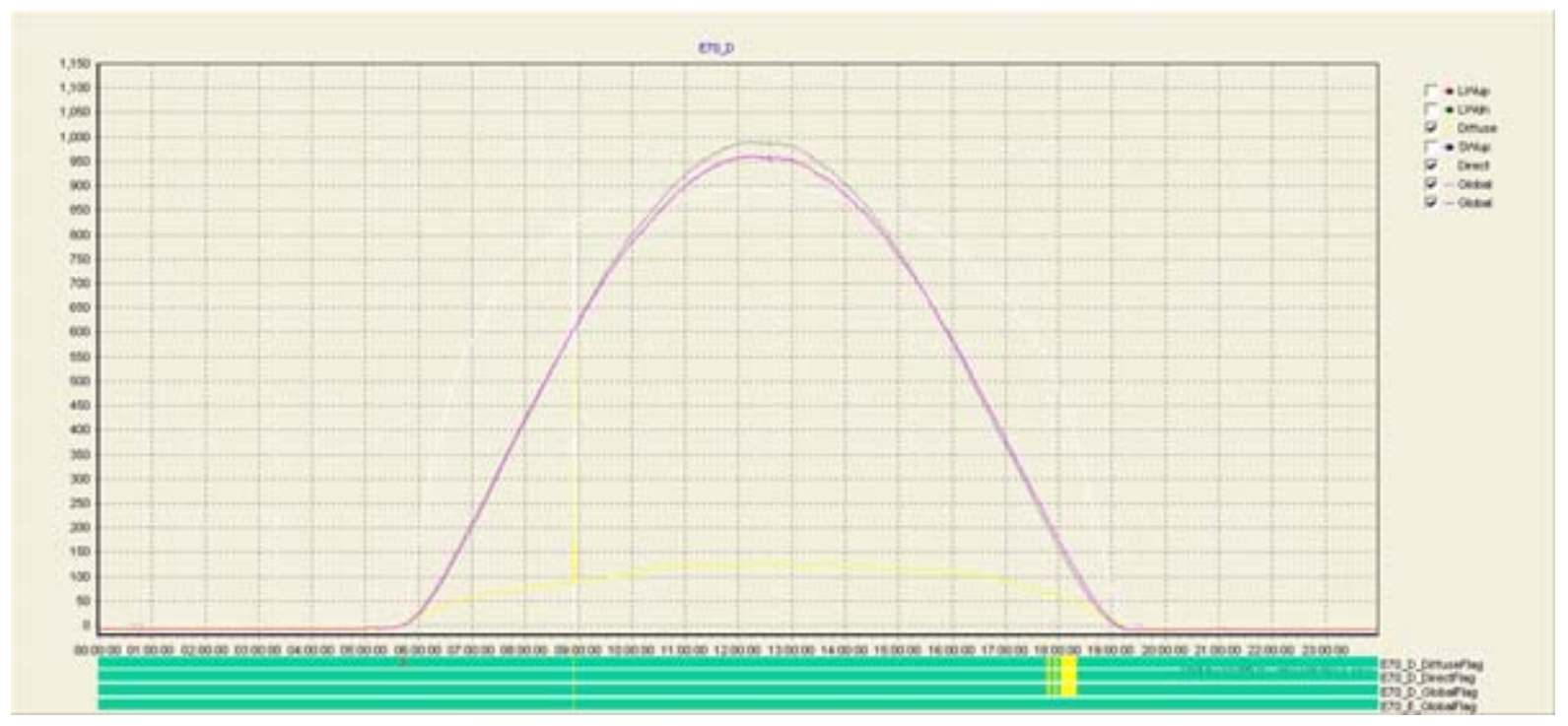

Figure 6. Typical sunny day at SGP, with Rs(45) data shown in grey and Rs(Z) shown in pink.

BRS, C1, and E13

15th Day, JUN 03 thru MAY 04

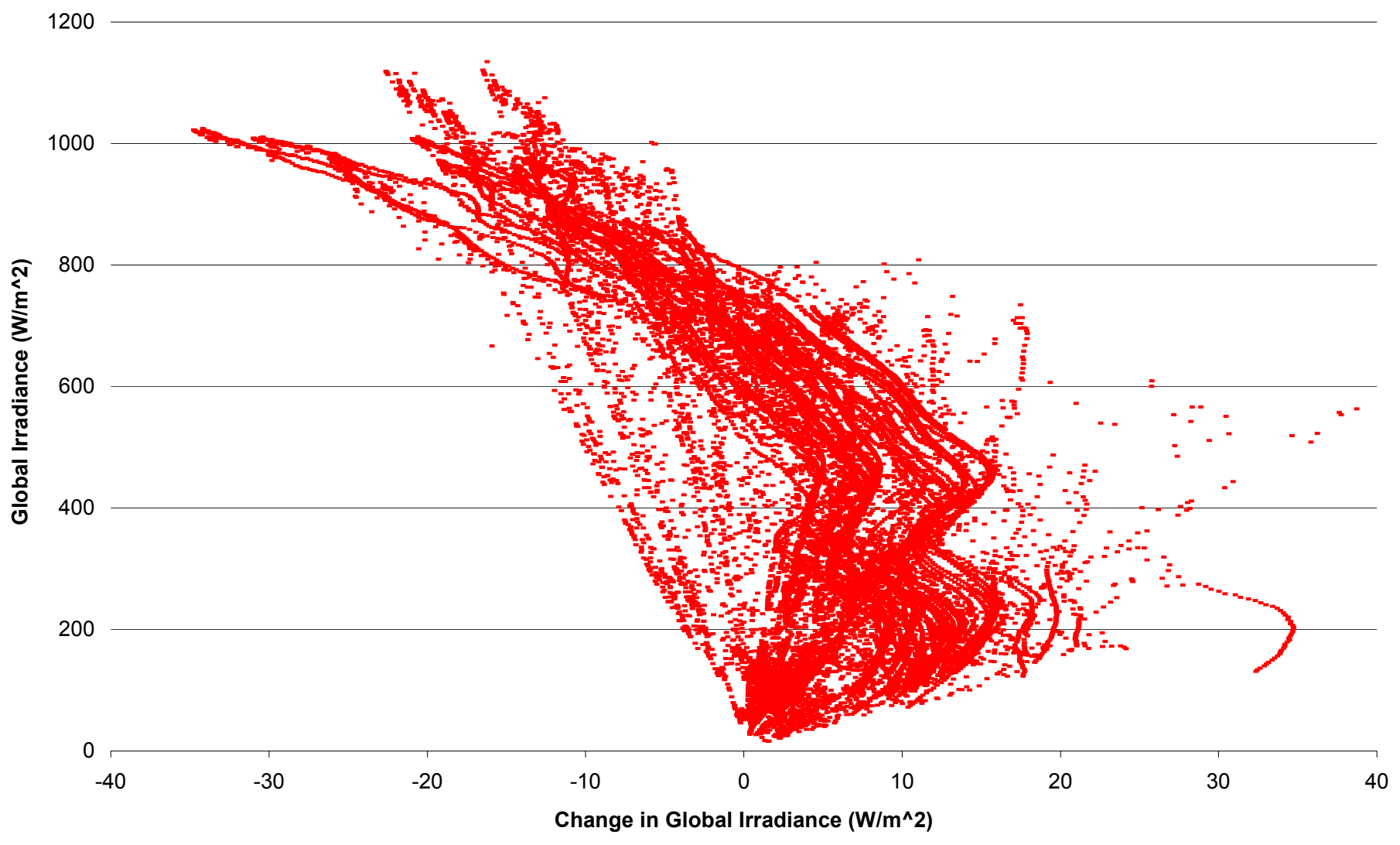

Figure 7. Scatter plot for data from the $15^{\text {th }}$ of each month during the test period.

Figure 7 shows how large the change in global irradiance can be in absolute terms in going from $\operatorname{Rs}(45)$ to $\operatorname{Rs}(Z)$. These data are from the three central stations only. They are all 
daytime data where the zenith angle was less than $80^{\circ}$ from the $15^{\text {th }}$ of all months of the test period. The $y$-axis is the average of the $\operatorname{Rs}(45)$ and $R s(Z)$ global data and the $\mathrm{X}$-axis is the change from $\operatorname{Rs}(45)$ to $\operatorname{Rs}(Z)$.

BRS, C1, and E13

15th Day, JUN 03 thru MAY 04

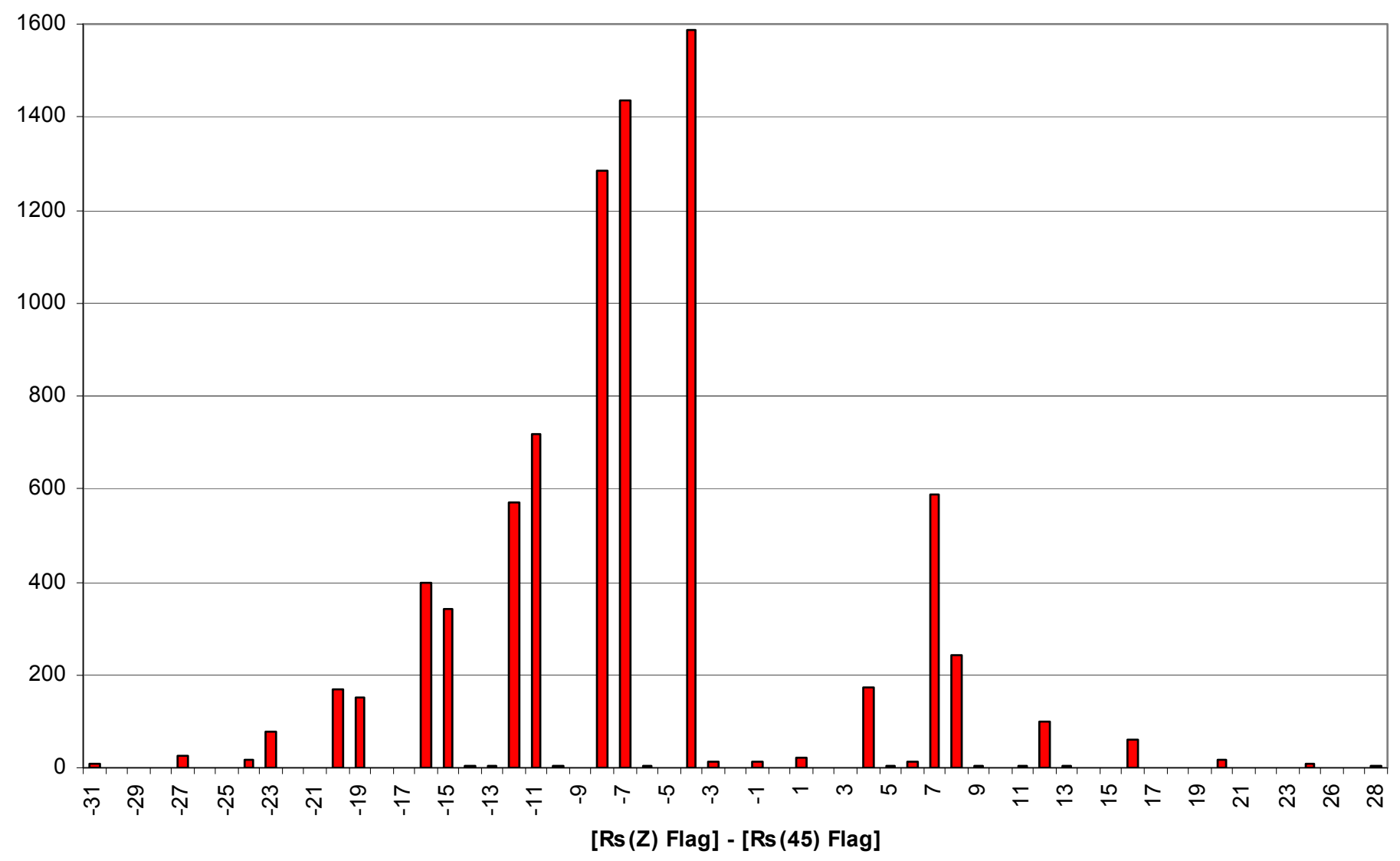

Figure 8. Histogram of occurrences of the change in SERI QC flags.

Figure 8 uses the same dataset as Figure 7. Figure 8, however, is a histogram of the change in SERI QC flags from a global measurement that uses Rs(45) to one that uses an Rs(Z). Because some $65 \%$ of the data saw no change in their flag after going to a reading with $\operatorname{Rs}(Z)$, including these data in Figure 8 would have detracted from the resolution of the graph. They were, therefore, not included. Ten outlying data points are not shown in Figure 8 to preserve resolution. 
Table 7. Same Data as in Figure 8, Except with 'Zero' Occurrences and Outliers Shown

\begin{tabular}{|c|c|}
\hline Bin & Frequency \\
\hline-31 & 7 \\
\hline-30 & 0 \\
\hline-29 & 0 \\
\hline-28 & 2 \\
\hline-27 & 27 \\
\hline-26 & 0 \\
\hline-25 & 0 \\
\hline-24 & 19 \\
\hline-23 & 78 \\
\hline-22 & 0 \\
\hline-21 & 0 \\
\hline-20 & 170 \\
\hline-19 & 152 \\
\hline-18 & 1 \\
\hline-17 & 0 \\
\hline-16 & 396 \\
\hline-15 & 341 \\
\hline-14 & 3 \\
\hline-13 & 3 \\
\hline-12 & 572 \\
\hline-11 & 720 \\
\hline-10 & 5 \\
\hline-9 & 0 \\
\hline-8 & 1283 \\
\hline-7 & 1435 \\
\hline-6 & 3 \\
\hline-5 & 2 \\
\hline-4 & 1588 \\
\hline-3 & 12 \\
\hline-2 & 1 \\
\hline-1 & 13 \\
\hline
\end{tabular}

\begin{tabular}{|c|c|}
\hline Bin & Frequency \\
\hline 0 & 15471 \\
\hline 1 & 20 \\
\hline 2 & 1 \\
\hline 3 & 0 \\
\hline 4 & 172 \\
\hline 5 & 5 \\
\hline 6 & 11 \\
\hline 7 & 586 \\
\hline 8 & 241 \\
\hline 9 & 6 \\
\hline 10 & 2 \\
\hline 11 & 6 \\
\hline 12 & 99 \\
\hline 13 & 5 \\
\hline 14 & 0 \\
\hline 15 & 0 \\
\hline 16 & 59 \\
\hline 17 & 2 \\
\hline 18 & 0 \\
\hline 19 & 0 \\
\hline 20 & 19 \\
\hline 21 & 0 \\
\hline 22 & 0 \\
\hline 23 & 0 \\
\hline 24 & 10 \\
\hline 26 & 0 \\
\hline 27 & 0 \\
\hline 28 & 5 \\
\hline More & 10 \\
\hline
\end{tabular}

The data in their entirety, however, can be seen in Table 7. Notice that there are over 15,000 data points whose flags remained the same. Also since a smaller flag is an improvement, the negative change means the Rs function improved the data quality just as in Table 6. 


\section{Conclusion}

Applying the Rs $(Z)$ function to the global irradiance data reduces the measurement uncertainties due to variations of pyranometer angular response. In particular, the Rs $(Z)$ function improves unshaded pyranometer measurement accuracies under clear sky conditions when compared with coincident observations of direct normal and diffuse horizontal irradiances. Overall, however, most daytime data quality flags remained unchanged for solar zenith angles much less than $80^{\circ}$.

The greatest improvement appears for "questionable" (yellow data flag) data because these measurements typically occur during three-component consistency tests near $80^{\circ}$ solar zenith angle when the Rs(45) would produce the largest discrepancies from ideal pyranometer angular response.

Relatively little change was observed in the "failed" (red) data. No site saw an improvement greater than $0.37 \%$ or a degradation of less than $0.2 \%$. The improvement could be partially attributed to three component failures of severe magnitude, flags of $11 \%$ error or more. The case where some sites actually saw their amount of red data increase - namely E21, E24, and E27 - is harder to explain. It could be due to the different time-response characteristics of the PSP, NIP, and 8-48 radiometers and the resulting measurements under rapidly changing cloud conditions. Also, the Rs function does not consider ambient parameters such as longwave flux and humidity, which determine pyranometer thermal offsets. In any case, the number of red data fluctuations between $\operatorname{Rs}(45)$ and $\operatorname{Rs}(Z)$ analyses are minor.

There are some small but notable changes in the black (missing) data. For the $\operatorname{Rs}(Z)$ dataset, some data were removed that were not removed from the Rs(45) dataset. This was done during instrument change outs to ensure that the correct Rs function was being applied to the instruments that took the reading. These omissions were very small.

The Rs function had an inconsequential effect on cloudy sky data; when these data were not flagged as below empirical limits - which can be frequent - they were generally good (green), both with the Rs(Z) and the Rs(45).

Each pyranometer behaves differently, so associated improvement with the Rs function depends heavily on the measurement characteristics of a particular instrument.

\section{References}

1. Reda, I. (1998). Improving the Accuracy of Using Pyranometers to Measure the Clear Sky Global Solar Irradiance. Golden, CO: National Renewable Energy Laboratory. 24 pp. Report Number: NREL/TP-560-24833.

2. Myers, D.; Andres, A.; Reda, I.; Wilcox, S. "Optical Radiation Measurements for Photovoltaic Applications: Instrumentation Uncertainty and Performance.” Presented at the SPIE International Symposium on Optical Science \& Technology, August 2-6, 2004, Denver, CO. 
3. Wilcox, S.; Myers, D.; Al-Abbadi, N.; Mahfoodh, M. B. (2001). "Improving Global Solar Radiation Measurements Using Zenith Angle Dependent Calibration Factors." CampbellHowe, R., (ed.) Proceedings of Forum 2001 Solar Energy: The Power to Choose; Including Proceedings of ASES Annual Conference and Proceedings of the 26th National Passive Solar Conference, April 21-25, 2001, Washington, DC. Boulder, CO: American Solar Energy Society and Washington, DC: American Institute of Architects Committee on the Environment, pp. 267-271.

4. The Eppley Laboratory Inc. Web site. www.eppleylab.com. Accessed June 24, 2004.

5. Incpera, F.P.; DeWitt, D.P. (2002). Fundamentals of Heat and Mass Transfer. New York: J. Wiley. 5th ed. $981 \mathrm{pp}$.

6. Reda, I.; Stoffel, T.; Myers, D. (2003). "Method to Calibrate a Solar Pyranometer for Measuring Reference Diffuse Irradiance.” Solar Energy vol. 74, no. 2, pp. 103-112.

7. SIRS Instrument Logs. http://198.124.96.210/Instrument_logs/SIRSilog/sirs ilog_list.htm June 1, 2004-August 17, 2004. Instrument change out dates.

8. Maxwell, E.; Wilcox, S.; Rymes, M. (1993). "Users Manual for SERI QC Software." NREL TP 463- 5608.

9. Fröhlich, C., 1977, 'World Radiometric Reference', in: WMO/CIMO Final Report, WMO No. 490, 97-100. (PMOD/WRC intern: 545a)

10. Fröhlich, C., 1991, History of solar radiometry and the World Radiation Reference, Metrologia 28, 111-115. (PMOD/WRC intern: 650)

11. Fröhlich, C., Philipona, R., Romero, J., and Wehrli, C., 1995, Radiometry at the Physikalisch-Meteorologisches Observatorium Davos and the World Radiation Center, Optical Engineering 34, 2757-2766. (PMOD/WRC intern: 674)

12. NREL, 1993. Users manual for SERI QC software: assessing the quality of solar radiation data., NREL/TP-463-5608. 191 pp. National Renewable Energy Laboratory, December. (Available from the Renewable Resource Data Center, http://rredc.nrel.gov/solar/\#publications) 


\section{REPORT DOCUMENTATION PAGE}

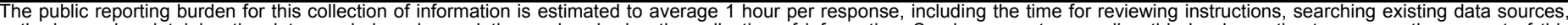

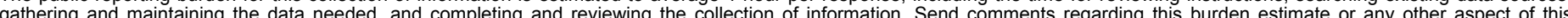

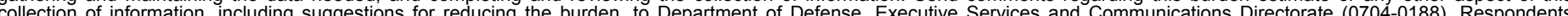

should be aware that notwithstanding any other provision of law, no person shall be subject to any penalty for fail

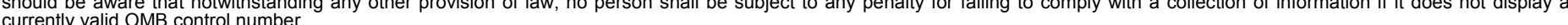

PLEASE DO NOT RETURN YOUR FORM TO THE ABOVE ORGANIZATION.

\begin{tabular}{l|l|l|l} 
1. REPORT DATE $(D D-M M-Y Y Y Y)$ & 2. & REPORT TYPE & 3. DATES COVERED (FrOm - TO)
\end{tabular}

February 2006

Technical Report

4. TITLE AND SUBTITLE

A Case Study of the Application of a Modified Method to Measure

Global Solar Irradiance 5a. CONTRACT NUMBER

DE-AC36-99-G010337

5b. GRANT NUMBER

5c. PROGRAM ELEMENT NUMBER

5d. PROJECT NUMBER

NREL/TP-560-37184

5e. TASK NUMBER

WUID5600

5f. WORK UNIT NUMBER
7. PERFORMING ORGANIZATION NAME(S) AND ADDRESS(ES)

National Renewable Energy Laboratory

1617 Cole Blvd.

Golden, CO 80401-3393
8. PERFORMING ORGANIZATION REPORT NUMBER

NREL/TP-560-37184

9. SPONSORING/MONITORING AGENCY NAME(S) AND ADDRESS(ES)

10. SPONSOR/MONITOR'S ACRONYM(S) NREL

11. SPONSORING/MONITORING AGENCY REPORT NUMBER

12. DISTRIBUTION AVAILABILITY STATEMENT

National Technical Information Service

U.S. Department of Commerce

5285 Port Royal Road

Springfield, VA 22161

13. SUPPLEMENTARY NOTES

14. ABSTRACT (Maximum 200 Words)

Case study that examines the application of a pyranometer responsivity function to data from 23 measurement stations in the Southern Great Plains.

15. SUBJECT TERMS

pyranometer; irradiance; radiometer; thermopile

\begin{tabular}{|c|c|c|}
\hline $\begin{array}{l}\text { a. REPORT } \\
\text { Unclassified }\end{array}$ & $\begin{array}{l}\text { b. ABSTRACT } \\
\text { Unclassified }\end{array}$ & $\begin{array}{l}\text { c. THIS PAGE } \\
\text { Unclassified }\end{array}$ \\
\hline
\end{tabular}

\begin{tabular}{l|l|} 
17. LIMITATION & 18. \\
OF ABSTRACT & OF PAGES \\
UL &
\end{tabular}

19a. NAME OF RESPONSIBLE PERSON

19b. TELEPHONE NUMBER (Include area code) 